\title{
Sulfur/Sisal Fiber Carbons Composites as Anode Materials for Lithium-ion Batteries
}

\author{
Rui Du ${ }^{1,2}$, Zhangfa Tong ${ }^{1}$, Chun Wei ${ }^{1,2}$, Aimiao Qin ${ }^{2 *}$, Gaige Zhang ${ }^{2}$ \\ ${ }^{1}$ School of Chemistry and Chemical Engineering, Guangxi University, Nanning 530001, PR China \\ ${ }^{2}$ Guangxi Ministry-Province Jointly-Constructed Cultivation Base for State Key Laboratory of \\ Processing for Non-ferrous Metal and Featured Materials, Guilin University of Technology, Guilin \\ 541004, PR China. \\ *E-mail: $\underline{317881264 @ q q . c o m}$
}

doi: $10.20964 / 2017.06 .40$

Received: 7 March 2017 / Accepted: 18 April 2017 / Published: 12 May 2017

The sulfur/sisal fiber carbons composites were prepared by pyrolysis and hydrothermal method. The structure of the sulfur/SFCs composites were characterized by X-ray diffraction and scanning electron microscopy, and the electrochemical performance of the sulfur/SFCs composites was tested by constant current charge-discharge tests. The initial discharge specific capacity of the sulfur/SFCs composites is $1223 \mathrm{mAhg}^{-1}$ and the reversible capacity of the sulfur/SFCs composites is about $400 \mathrm{mAhg}^{-1}$. The charge-discharge efficiency closed to $90 \%$ after the first cycle.

Keywords: Sulfur, sisal fiber carbons, hydrothermal, anode materials

\section{$\underline{\text { FULL TEXT }}$}

(C) 2017 The Authors. Published by ESG (www.electrochemsci.org). This article is an open access article distributed under the terms and conditions of the Creative Commons Attribution license (http://creativecommons.org/licenses/by/4.0/). 